An Informal Case Study: My Life in Physics

\author{
Christine Celata
}

Staff Physicist

Lawrence Berkeley National Laboratory 


\section{Early Education}

Public schools, Dedham, Massachusetts, Sputnik era

- great school, lots of science \& math

- woman math, biology, general science teachers in junior high

- valedictorian, high SATs

\section{Colby College, Waterville, Maine (1966-1970)}

- small liberal arts school, physics undistinguished at that time

\section{Why was I there?}

gender

class

- learned "male" stuff-- shop tools, soldering, physics 


\section{Graduate School}

\section{University of Maryland at College Park, Physics Dept.}

- 14 of $200+$ physics grad students were women

- told I was chosen for my gender

"I don't want to waste my money on a female graduate student. They just get married and leave the field." U. Maryland, c. 1975

I stopped looking for a thesis advisor for $\mathbf{2}$ years.

- PhD in theoretical plasma physics in 1978 


\section{The Job Search}

\section{Applied for 5 jobs after PhD (1978). Offered 2.}

About the other 3:

"Will you go to bed with me? No? I can't consider you for this position because I like you too much. It wouldn't be fair to the other applicants." $\quad$ Princeton Plasma Physics Lab, 1978

"I don't want to hire any single women-- they can't get their work done here because the men bother them too much."

Naval Research Lab, 1978

"I won't consider you for this job. The presence of a woman in the lab would be disruptive." MIT Plasma Physics Institute, 1978

I accepted a position as a professor at Dartmouth rejecting research positions. I had been treated relatively normally in academia, and wanted more control. I was interviewed for the job because I am female. 


\section{Part-time work \& Family}

1983 - 1988 Computational theorist in Heavy Ion Fusion

I was treated fairly, and advanced quickly until:

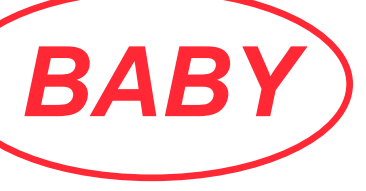

(1988)

"I'm disappointed in you. I thought you were more than just one of the sheep." A colleague; later to be my boss

"Part time people are not worth having. They work only their assigned hours, while full time people work much more." My boss's boss

"Why should we keep you when we can get someone normal?" My boss

"It is not in the interest of the Laboratory to set the precedent of being flexible to a woman with a child." (Direct quote: Head of HR, who shortly thereafter became head of the Diversity Office.) 


\section{Part-time work (1988 - 2002)}

All of the women who had tried to be part-time at LBNL, as far as I could find, had to leave.

I was rescued by a white male supervisor who didn't like what was being done to me. He created a job for me in management \& experimental work, though I had no training in those areas.

Worked part-time for 14 years. Appraisals were excellent, but raises suffered. Arrangement worked well, except for this.

All flexible work pilot programs just disappeared at LBNL. Limited telecommuting exists. 


\title{
The Good Guys
}

\author{
Alex Dragt \\ Jose Alonso \\ Roy Kerth
}

Swapan Chattopadhyay, Andy Sessler, Dennis Hall

Ben Feinberg ( $\&$ the Bevatron group)

\section{Roger Bangerter \\ Bill Barletta}

and all of the colleagues who provided moral support.

You need to be rescued by a male at the top-- the rules are not superceding the culture. But-- there are many fair people, and some have power. 


\section{About the environment at LBNL...}

The work is great. In between glaring problems (not all mentioned here) have been many years of good work.

My division-- 1 woman career scientist out of 51

Hiring practices much better than when I came, but not there yet! One problem is the practice of only taking the "best candidate".

My career has been frequently interrupted, chaotic, both for problems and for opportunities connected with being female. 


\section{The face of my field: 2004 Heavy lon Fusion Symposium Picture}

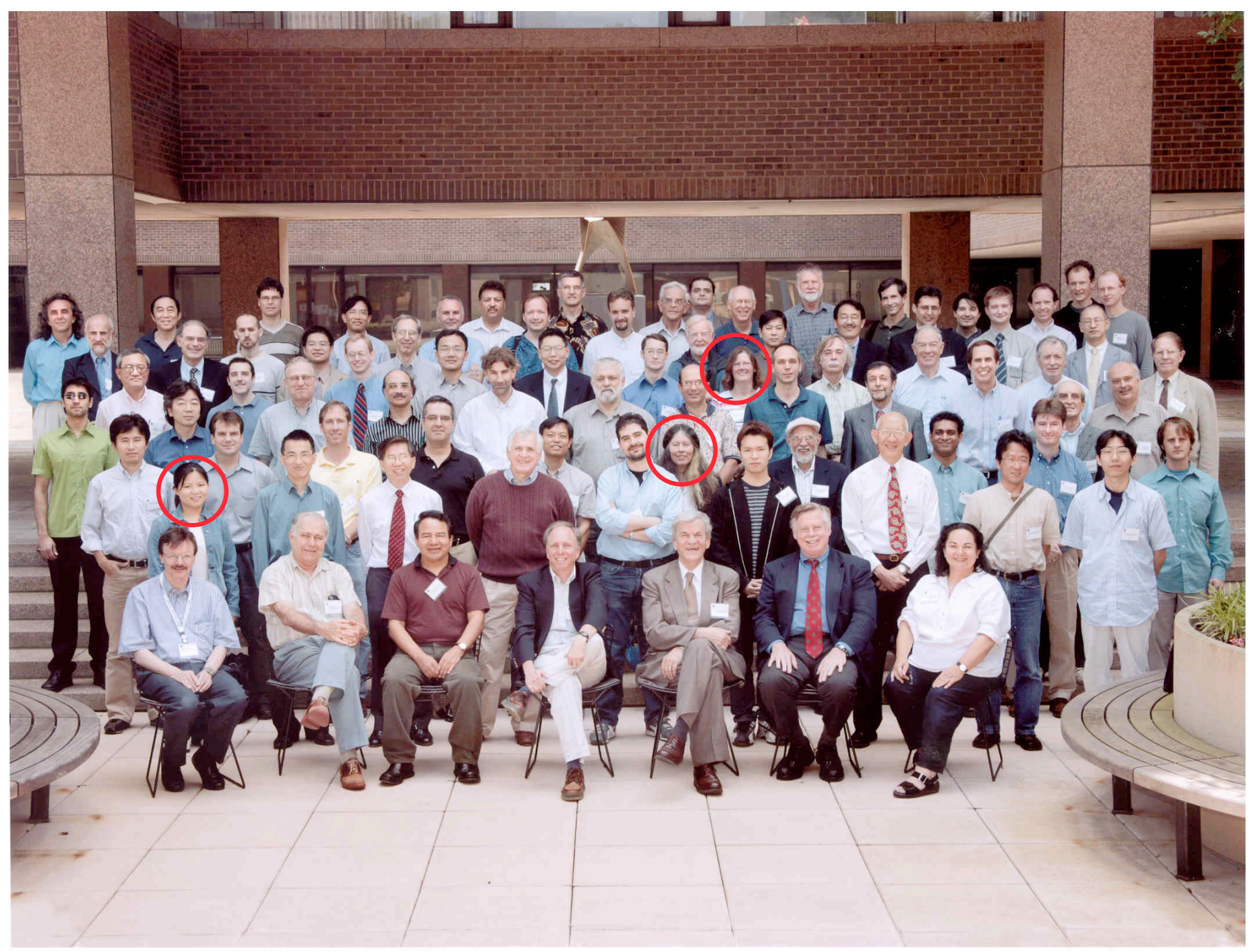




\section{Some Conclusions}

Hiring practices are much better than they were 20 years ago at LBNL, but we definitely aren't there yet.

Everything still depends on who is at the top, not on structure.

Having a balanced family/work life is not supported.

What you need to survive is support, ability, and especially, persistence! 


\section{Backup Slides}




\section{My chaotic career at LBNL}

1983 - 1988 Computational theorist in Heavy Ion Fusion

1988 - 1994 Project manager \& experimentalist (!) at the Bevatron (accelerator R\&D)

- improving beam for medical treatments, nuclear physics

1994 - 1997 Deputy head of Accelerator \& Fusion Research division

1997 - now Computational theorist in Heavy lon Fusion Head of Advance Planning Deputy program head Deputy division head 